\title{
Rapid estimation of excess mortality: nowcasting during the heatwave alert in England and Wales in June 2011
}

\author{
Helen K Green, ${ }^{1}$ Nick J Andrews, ${ }^{2}$ Graham Bickler, ${ }^{3}$ Richard G Pebody ${ }^{1}$
}

'Department of Respiratory Diseases, Health Protection Agency, London, UK ${ }^{2}$ Statistics Unit, Health Protection Agency, London, UK ${ }^{3}$ Health Protection Agency South East, London, UK

\section{Correspondence to}

Dr Richard Pebody, Department of Respiratory Diseases, Health Protection Agency, 61 Colindale Avenue, London NW9 5EQ, UK; richard.pebody@hpa.org.uk

Accepted 9 April 2012 Published Online First 5 July 2012

\section{(2) UNLOCKA}

This paper is freely available online under the BMJ Journals unlocked scheme, see http:// jech.bmj.com/site/about/ unlocked.xhtml

\begin{abstract}
Background A Heat-Health Watch system has been established in England and Wales since 2004 as part of the national heatwave plan following the 2003 Europeanwide heatwave. One important element of this plan has been the development of a timely mortality surveillance system. This article reports the findings and timeliness of a daily mortality model used to 'nowcast' excess mortality (utilising incomplete surveillance data to estimate the number of deaths in near-real time) during a heatwave alert issued by the Met Office for regions in South and East England on 24 June 2011.
\end{abstract}

Methods Daily death registrations were corrected for reporting delays with historical data supplied by the General Registry Office. These corrected counts were compared with expected counts from an age-specific linear regression model to ascertain if any excess had occurred during the heatwave.

Results Excess mortality of 367 deaths was detected across England and Wales in $\geq 85$-year-olds on 26 and 27 June 2011, coinciding with the period of elevated temperature. This excess was localised to the east of England and London. It was detected 3 days after the heatwave.

Conclusion A daily mortality model was sensitive and timely enough to rapidly detect a small excess, both, at national and regional levels. This tool will be useful when future events of public health significance occur.

\section{INTRODUCTION}

The 2003 European-wide heatwave and the resulting substantial excess mortality highlighted the significant impact these sudden events can have upon the general population. ${ }^{1-3}$ This notable climatic event is predicted to become annual by the $2080 \mathrm{~s}^{4}$ due to changes in climate; indeed, the UK has experienced some notably warm summers since 2003, which have been associated with excess morbidity and mortality. ${ }^{5}$ In response, a HeatHealth Watch system ${ }^{6}$ was established in 2004 in England and Wales as part of the heatwave plan which operates from 1 June to 15 September each year. Region-specific thresholds have been set for maximum daytime and minimum nighttime temperatures, above which heat could have a significant effect on health (table 1). A threshold breach alerts social and healthcare services which can then work to reduce the potential health impact by targeting specific actions to high-risk groups. In recent seasons, the development of a real-time age group and region-specific excess mortality surveillance system by the Health Protection Agency (HPA) became possible with the creation of the online death registration system by the General Registry Office (GRO) in 2009. Daily death data from this surveillance system has enabled rapid estimation of the mortality impact of public health events such as pandemic influenza and extreme temperature. ${ }^{5}$ This timely analysis can then be used to help guide and prioritise public health measures and identify vulnerable individuals. Reporting delays between the date of death and date of registration are inherent in the civil death registration process in England and Wales. Therefore, the process of nowcasting, predicting the number of deaths that occurred on a given day by adjusting available data for reporting delays, together with development of a daily surveillance system have been important to provide timely information on the health impact of an event, particularly if it is persisting. ${ }^{78}$

When a risk $\geq 60 \%$ of regional temperatures approaching the predefined Heat Watch thresholds was reached in London, southeast England, the east of England and the East Midlands on 24 June 2011, an alert was issued by the Met Office to inform social and healthcare services. ${ }^{6}$ This remained until the morning of 28 June 2011. This alert triggered the provision of daily GRO data to the HPA to enable daily estimation of excess mortality. This article outlines the key findings of this new daily mortality surveillance system, detailing if an excess was detected during this time, and how the system performed in near-real time.

\section{METHODS}

Following the trigger of the heatwave alert on 24 June 2011, a historical dataset of all daily death data in England and Wales back to 17 May 2011 was provided by the GRO to the HPA. To nowcast excess all-cause deaths (defined as observed deaths minus expected deaths), reporting delays between death and registration were accounted for by correcting the number of observed deaths each day. This was particularly important for younger age groups where registration delays can be long. ${ }^{9}$ Historical daily death data was supplied to the HPA by the Office for National Statistics (ONS) for the summers of 2010 and 2011 to develop an ageand region-specific delay correction factor. The observed delay factor was dependent upon the day of the week of death, age of the deceased and region where the death was reported. The method for how it was calculated is described elsewhere. ${ }^{5}$

After correcting historical data for delays, the data was used to establish a baseline by fitting an age-specific linear regression model within each 
Table 1 Maximum daily temperature $\left({ }^{\circ} \mathrm{C}\right)$ recorded in the regions of England and Wales during the heatwave alert in June $2011^{*}$

\begin{tabular}{|c|c|c|c|}
\hline \multirow[b]{2}{*}{ Region } & \multirow{2}{*}{$\begin{array}{l}\text { Heat-Health } \\
\text { Watch regional } \\
\text { heatwave daytime } \\
\text { threshold } \\
\text { values ('C) }\end{array}$} & \multicolumn{2}{|c|}{$\begin{array}{l}\text { Maximum daily } \\
\text { temperature }\left({ }^{\circ} \mathrm{C}\right)\end{array}$} \\
\hline & & $\begin{array}{l}26 \text { June } \\
2011\end{array}$ & $\begin{array}{l}27 \text { June } \\
2011\end{array}$ \\
\hline East of England & 30 & 29.0 & 31.9 \\
\hline East Midlands & 30 & 28.1 & 29.8 \\
\hline London & 32 & 28.7 & 31.4 \\
\hline Northeast England & 28 & 23.9 & 22.1 \\
\hline Northwest England & 30 & 25.1 & 27.0 \\
\hline Southeast England & 31 & 28.5 & 31.2 \\
\hline Southwest England & 30 & 27.6 & 24.8 \\
\hline West Midlands & 30 & 27.6 & 28.5 \\
\hline Yorkshire \& Humber & 29 & 27.8 & 29.6 \\
\hline Wales & 30 & 26.8 & 23.4 \\
\hline
\end{tabular}

The station for each region was chosen to be as representative as possible for each region as a whole. Bold values indicate exceedance of Heat-Health Watch regional threshold temperatures.

*Data provided by the Met Office National Climate Information Centre. Please note, this data is provisional and is still subject to quality control measures.

region to determine the expected number of deaths, excluding the days on which a heatwave alert was active from the baseline model. Daily data for deaths registered the previous day was further supplied after 24 June 2011 from Monday to Friday for 2 weeks and corrected for delays. Excess deaths during the heatwave period were estimated as observed delay-corrected deaths minus baseline deaths. Estimates of excess for England and Wales, overall, and by region were calculated. 95\% CIs were calculated based on the variability in deaths during the non-heatwave period. To determine whether any excess was significant, an upper 3SD limit was added to the baseline. 3SD was used to allow for multiple testing when assessing many age groups, regions and different days. The 2SD upper limit was also calculated to see if excess mortality was close to significance (above 2SD but $<3 S D$ ). The assessment of excess deaths was repeated daily for each new dataset supplied, with estimates given for deaths occurring up to two working days prior to the date of the dataset provision. Estimates given in this report are those as determined on 7 July 2011 when the final dataset was provided.
Mean and maximum Central England Temperatures (CET) ${ }^{10}$ were monitored for the duration of the heatwave. Provisional region-specific temperatures were provided by the Met Office National Climate Information Centre post-heatwave.

\section{RESULTS}

Temperatures were high on 26 and 27 June 2011, with mean CETs of $20.3^{\circ} \mathrm{C}$ and $22.0^{\circ} \mathrm{C}$ and maximum CETs of $26.7^{\circ} \mathrm{C}$ and $28.0^{\circ} \mathrm{C}$, respectively. Regionally, heatwave thresholds were exceeded on Monday 27 June in the east of England, southeast England, and Yorkshire \& Humber. No regional thresholds were exceeded on Sunday 26 June (table 1).

For the period when daily mortality data was available (17 May-5 July 2011), and after correcting the number of observed deaths each day for reporting delays, significant excess mortality (above the 3SD limit) was observed in $\geq 65$-year-olds across England and Wales on 26 and 27 June 2011, coinciding with the peak in mean CET (figure 1). This excess was detected by the daily model on 30 June ( 3 days later) when the model was run for the first time, once data was available and a baseline had been established. An estimated 367 excess deaths were calculated over this 2 -day period. This equates to $16.6 \%(367 / 2215)$ (95\% CI 9.7 to 23.4 ) of deaths in $\geq 65$-year-olds over these 2 days (figure 1). This compares with 299 of 3197 deaths $(9.4 \%, 95 \% \mathrm{CI}$ 4.5 to 14.2) detected between 30 June and 2 July 2009 during the 2009 heatwave. ${ }^{5}$

When age-group-specific excess was explored in more detail (data not shown), the excess was only significant in $\geq 85$-yearolds over the same time period. Two hundred and twenty-two of 1036 deaths $(21.4 \%, 95 \%$ CI 10.4 to 32.4$)$ in this age group were classified as excess.

When region-specific excess mortality was assessed, it was only significant in two regions in $\geq 65$-year-olds: the east of England on 27 June with 32 of 79 deaths excess (40.5\%, 95\% CI 17.7 to 63.3), and London on 28 June with 39 of 139 (28.1\%, 95\% CI 10.1 to 46.0). Although a significant excess was not seen in other regions, excess mortality during the heatwave was above a $2 \mathrm{SD}$ upper limit in four of the eight remaining regions (northwest England, southwest England, West Midlands and Yorkshire \& Humber). No significant excess was detected in any region in $<65$-year-olds.
Figure 1 Delay-corrected observed and predicted number of all-cause deaths in $<65$-yr-olds and $\geq 65$-yr-olds in England and Wales, and mean Central England Temperature from 24 May to 5 July 2011. The yellow arrow indicates when the heatwave alert was issued by the Met Office. Excess mortality (number of deaths greater than the prediction) is deemed significant if greater than the upper 3SD limit.

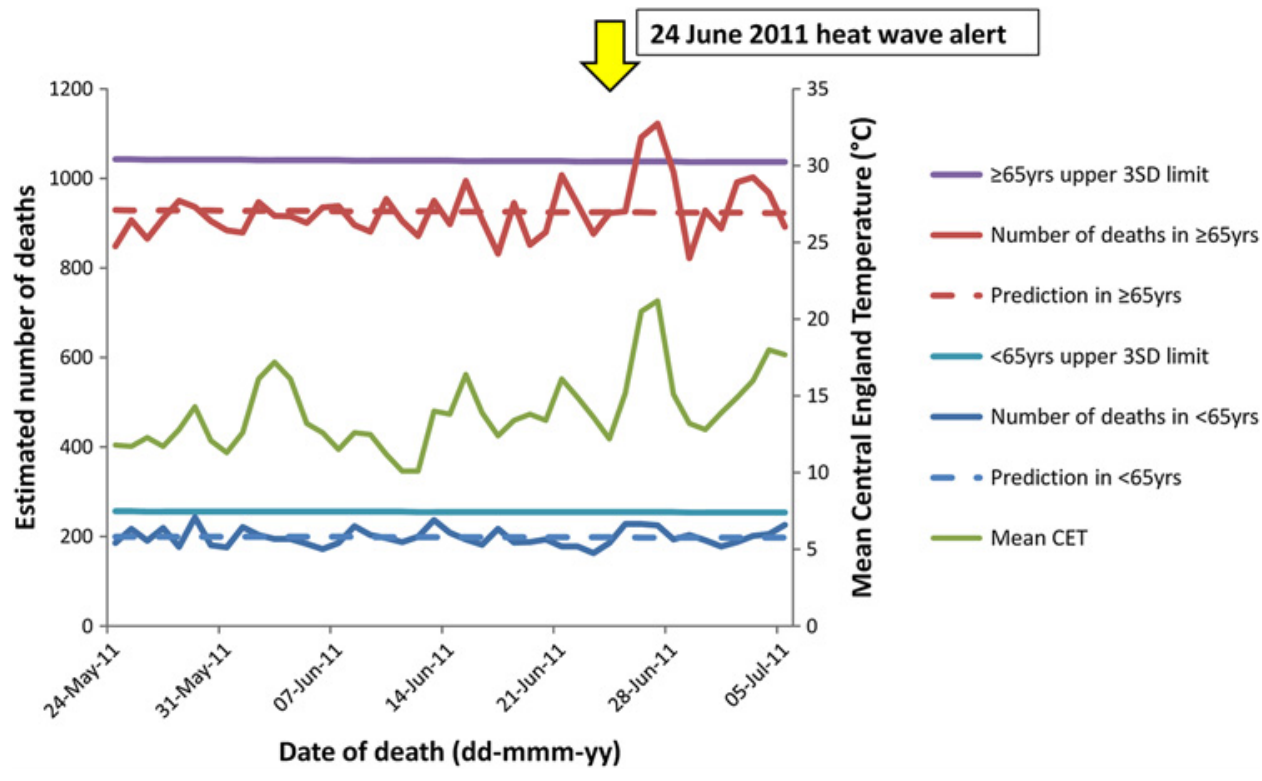




\section{DISCUSSION}

The UK experienced a heatwave alert in June 2011 which triggered various public health responses. Daily excess mortality reporting was switched on to enable nearreal-time monitoring of the population impact. Despite the alert lasting only four days, and temperature values increasing slightly above thresholds, the surveillance system was sensitive and timely enough to detect significant excess all-cause mortality within a short period ( 3 days) of the event. The observed excess was not detected in the weekly models run at the HPA over the same time period using the well-established Serfling model and the recently piloted EuroMOMO algorithm (data not shown). ${ }^{11} 12$

Furthermore, the new daily mortality surveillance system was able to describe which age groups and regions were affected. The observed excess in $\geq 65$-year-olds was primarily attributed to $\geq 85$-year-olds. The elderly are a key risk group susceptible to the effects of heatwaves and so it is not surprising they were affected. ${ }^{1}{ }^{13}$ The geographical distribution of observed excess in the east of England and London was consistent with the high regional temperatures observed, and also with heatwaveassociated community morbidity indicators at this time determined through the routine monitoring using HPA syndromic surveillance systems. ${ }^{14}$ Temperatures were notably high in the east of England, and rose above the $30^{\circ} \mathrm{C}$ regional threshold (maximum temperature of $31.9^{\circ} \mathrm{C}$ recorded), with 27 June 2011 recorded as the hottest day in the region for 5 years. ${ }^{15} \mathrm{~A}$ small delayed excess was seen in London one day after the heatwave, despite temperatures not increasing above the regional threshold of $32^{\circ} \mathrm{C}$. While temperature thresholds were breached in southeast England and Yorkshire \& Humber, no significant excess was detected in these regions, although excess mortality was above a 2SD upper limit in Yorkshire \& Humber, and so, close to significance.

The findings are consistent with the well-described epidemiology of heatwaves. ${ }^{5}$ Excess mortality detected by the daily model coincided with the period over which an alert was issued,

\section{What is already known on this subject}

- Heatwaves can have considerable implications on vulnerable sections of the population, and mortality usually rises within 24-48 $\mathrm{h}$ of temperature increases.

- A timely mortality surveillance system is key to rapidly detect and monitor the impact of heatwaves, which are predicted to increase in frequency with changes in climate.

\section{What this study adds}

- Excess deaths were detected during a heatwave alert in England and Wales in June 2011 when temperatures were elevated for a short period, enabling a rapid evaluation of the population health impact.

- Despite temperature values increasing only slightly above Heat Watch thresholds, a daily mortality model was sensitive and timely enough to nowcast small levels of excess mortality both in the elderly and in specific regions of England. confirming appropriate temperature thresholds set by the national heatwave plan. The provision of daily data by GRO and nowcasting through this system will be useful when future events of public health significance occur and prompt analysis is required, such as heatwaves, pandemic influenza and mass gatherings such as the 2012 London Olympics.

These findings add to the evidence of the rapid effect of short periods of high temperature on sectors of the population. With an increasing elderly population and future climate changes predicted, the importance of timely heatwave public health intervention measures and an associated robust real-time mortality surveillance system is highlighted.

Acknowledgements We are grateful to the Office for National Statistics for supplying historical death data, and the General Registry Office for providing us with the daily mortality data and enabling us to carry out this analysis. We are also grateful to the Met Office National Climate Information Centre for providing us with region-specific temperature data. We would like to thank our colleagues from the Real-time Syndromic Surveillance Team within the HPA for sharing relevant information from their systems, and in particular, to Alex Elliot and Gillian Smith for their review of the manuscript. Additionally, we would like to thank our colleagues, Pia Hardelid for previous model development work, and Virginia Murray, Katie Carmichael and John Watson for their review of the manuscript.

Contributors RP and NA initiated the study as part of the national heatwave plan in England and Wales. NA and HKG designed the model. HKG collated the data. HKG and NA analysed the data. HKG, NA and RP interpreted the data. HKG, NA and $\mathrm{RP}$ drafted the article. HKG, NA, GB and RP revised the article. The guarantor of the article is RP.

Competing interests None.

Provenance and peer review Not commissioned; externally peer reviewed.

\section{REFERENCES}

1. Johnson H, Kovats S, McGregor G, et al. The impact of the 2003 heat wave on daily mortality in England and Wales and the use of rapid weekly mortality estimates. Euro Surveill 2005;10:558. http://www.eurosurveillance.org/ViewArticle.aspx? Articleld $=558$

2. Robine JM, Cheung SLK, Le Roy S, et al. Death toll exceeded 70,000 in Europe during the summer of 2003. Comptes Rendus Biologies 2008;331:171-8. http:// www.sciencedirect.com/science/article/pii/S1631069107003770

3. D'Ippoliti D, Michelozzi P, Marino C, et al. The impact of heat waves on mortality in 9 European cities: results from the EuroHEAT project. Environ Health 2010;16:37.

4. Department of Health. Heatwave Plan For England. 2011. http://www.dh.gov.uk/ prod consum dh/groups/dh digitalassets/documents/digitalasset/dh 127235.pdf (accessed Jul 2011).

5. Health Protection Agency. Chemical Hazards and Poisons report: Rapid estimation of excess mortality in England and Wales during the heatwave of June $30^{\text {th }}$ to July $2^{\text {nd }}$ 2009. 2010 http://www.hpa.org.uk/web/HPAwebFile/HPAweb_C/1274091561553 (accessed July 2011).

6. Met Office. Heat-Health Watch. http://www.metoffice.gov.uk/weather/uk/ heathealth/ (accessed Jul 2011).

7. Nicoll A, Ammon A, Amato Gauci A, et al. Experience and lessons from surveillance and studies of the 2009 pandemic in Europe. Public Health 2010;124:14-23.

8. Donker T, van Boven M, van Ballegooijen WM, et al. Nowcasting pandemic influenza A/H1N1 2009 hospitalisations in the Netherlands. Eur J Epidemiol 2011;26:195-201.

9. Devis T, Rooney C. The time taken to register a death. Popul Trends 1997:88:48-55.

10. Met Office. Hadley Centre Central England Temperature (HadCET) Dataset. http://www.metoffice.gov.uk/hadobs/hadcet/index.html (accessed Jul 2011)

11. Serfling RE. Methods for current statistical analysis of excess pneumonia-influenza deaths. Public Health Rep 1963;78:494-506. http://www.ncbi.nlm.nih.gov/pmc/ articles/PMC1915276/pdf/pubhealthreporig00078-0040.pdf

12. EuroMoMo. European Monitoring Of Excess Mortality For Public Health Action. http://www.euromomo.eu/ (accessed Jul 2011).

13. Rooney C, McMichael AJ, Kovats RS, et al. Excess mortality in England and Wales and in greater London, during the 1995 heat wave. J Epidemiol Community Health 1988;52:482-6.

14. Health Protection Agency. Real-Time Syndromic Surveillance. http://www.hpa org.uk/Topics/InfectiousDiseases/InfectionsAZ/RealtimeSyndromicSurveillance/ (accessed Oct 2011).

15. BBC Weather. UK Review—June 2011. 2011. http://news.bbc.co.uk/weather/hi/ uk_reviews/newsid_9531000/9531298.stm (accessed Jul 2011). 